\title{
The effects of sounds and food odour on crowd behaviours in urban public open
}

\section{spaces}

\author{
Meihui BA ${ }^{a^{*}}$, Jian KANG ${ }^{b^{*}}$, Zhongzhe $\mathrm{LI}^{\mathrm{a}}$
}

${ }^{a}$ Key Laboratory of Cold Region Urban and Rural Human Settlement Environment Science and Technology, Ministry of Industry and Information Technology, School of Architecture, Harbin Institute of Technology, Harbin, China.

${ }^{b} U C L$ Institute for Environmental Design and Engineering, University College London (UCL), London, United Kingdom.

"Corresponding author: Meihui BA, bameihui@hotmail.com, School of Architecture, Harbin Institute of Technology, NO.66 Xi Da Zhi Street, Harbin, China; Jian KANG, J.kang@ucl.ac.uk, UCL Institute for Environmental Design and Engineering, The Bartlett, University College London (UCL), London WC1H 0NN, United Kingdom. Tel: +44 (0)20 31087338.

\begin{abstract}
Few studies have investigated the integrated effects of sound and odour on people with the purpose of improving the use of urban spaces. Therefore, this study aimed to provide further insight into such effects from the perspective of crowd behaviour. A covert behavioural observation experiment was conducted in a typical urban commercial pedestrian street, using the smell of a bakery as the odour source, while reproducing typical urban sound sources of music and fan sound (along with a condition where no sound was played) with and without odour. The present results show that for crowd path, in the no-odour condition, playing music significantly attracted the crowd, while fan sound tended to make the crowd path farther away from the sensory sources. With the bakery odour, individuals approached the sensory sources closer when playing the sound, whether it was music or fan sound. With regard to crowd speed, music significantly reduced it and the greater the proximity to the sound source, the slower the crowd speed. Fan sound increased the crowd speed, which was significantly higher in the presence rather than absence of bakery odour, and the average speed decreased gradually as proximity to the sensory sources increased. Finally, with regard to the duration time of the crowd, it increased with music and decreased with fan sound. The bakery odour also significantly increased the duration time. However, the interaction effect between sound and odour on crowd speed and duration time was not significant.
\end{abstract}

Keywords: sounds; food odour; crowd behaviour; urban public open spaces 


\section{Introduction}

Urban public open spaces are fundamental to the existence, operation, and development of a city [1]. Different sensory stimuli constantly affect people's way of life. Therefore, increasing attention has been paid to the sensory design of urban public open spaces. However, particularly prominent at present is the problem of overemphasizing visual perception while overlooking other sensory aspects, which leads to the fulfilment of appearance requirements and neglect of users' other sensory and psychological needs [2].

Among the five senses, vision, audition, and olfaction have features that are diametric to those of taste and touch in experiencing the outside world. The former three often involve unconscious behaviour and cannot always be avoided at the beginning of an experience; the latter two are more dependent on people's subjective will [3]. Taste and touch are somewhat limited in their ability to grasp the external environment, whereas vision, audition, and olfaction are important for perceiving the environment [4]; further, the use of multiple senses allows one to receive more profound and comprehensive information [5]. A large number of previous studies on multi-senses have mainly focused on audio-visual [6-11] and visual-olfactory interactions [12-16]; however, research on the interaction between audition and olfaction is limited. For example, Jiang et al. examined the influence of rose odour and visual factors on the perception of traffic noise [17], and $\mathrm{Ba}$ and Kang studied the interaction between sound and odour in an urban environment both in a laboratory setting and in the field $[18,19]$. These experiments confirm that different combinations of auditory and olfactory factors can influence individuals' psychological parameters and thereby affect their subjective evaluation.

Changes in the sensory environment affect individuals psychologically, and changes in psychological perception inevitably result in behavioural changes. Behaviour constitutes a key component of the sensory environment and plays an important role in assessing it. However, because of the lack of research on crowd behaviour in urban sensory environments, the design of public open spaces is unsatisfactory [20]. Therefore, it is necessary to study crowd behaviour in urban sensory environments.

According to the object of study, behaviours can be divided into individual and crowd behaviours. Individual behaviour generally refers to a person's attitude or performance under specific circumstances, which is largely random under the influence of the environment [21]. Crowd behaviour refers to a crowd's attitude or performance, which can be composed of certain regularities under the influence of the environment [22,23]. Therefore, crowd behaviour, rather than individual behaviour, is often studied in research on urban public open spaces [24,25]. Depending on its characteristics, crowd behaviour also includes movement and action [26]. Movement behaviour is categorized as movement or non-movement. The path and speed reflect the change rules of movement while duration time reflects the change rules of 
non-movement; these variables are common research objects of movement behaviour [27]. Action behaviour includes sitting, standing, watching, and so on [24,28]. In addition, movement behaviour can better reflect the overall trend of the population, and the affected scope and degree of action behaviour are relatively small. Studies have shown that the sensory environment can affect people's behaviour. In terms of the influence of the sound environment, music is a common sound stimulus.and can cause people to have tendency behaviour to the sound source and reduce their walking speed, and the crowd density of sitting behaviour decreases as the distance from the sound source increases [27,29]. Furthermore, music as well as its type can increase the amount of time people spend at a location, including restaurants, tunnels, and city squares [27,30,31]. The odour environment also has an impact on behaviour, and people's evaluations and behaviours are different in shopping malls with and without an odour [32]. Previous research on the interactive effect of sound and odour on behaviour is scarce and focuses mainly on the field of sales. However, a study found that different combinations of sound and smell could change people's purchasing power and time spent in a shopping mall [33]. Overall, there is limited research on the relationship between sound and odour and their effect on crowd behaviour for improving the utilization of urban public open spaces.

The present study conducted a covert behavioural observation experiment in a typical urban commercial pedestrian street, using the smell of a bakery as the odour source, while reproducing typical urban sound sources of music and fan sound (along with a no-sound condition), with and without odour. The aim was to examine the regularity of crowd movement behaviour under the interaction of sound and odour, so as to improve the utilization of urban public open spaces. The research questions addressed in this study were:

(1) What is the interaction effect of sound and odour on the crowd path?

(2) What is the interaction effect of sound and odour on the crowd speed?

(3) What is the interaction effect of sound and odour on the duration time of a crowd?

\section{Materials and methods}

\subsection{Case study site and odour source selection}

In real-life situations, sound sources are abundant in urban public open spaces, and a situation involving a single sound source or silence almost never exists. In comparison, an odour source is easier to control. Moreover, in practice, it is difficult to find comparable natural conditions in which the sound sources are the same but the odour sources are different or vice versa. Thus, the experimental site in the field was selected such that the presence or absence of the 
odour source could be controlled. Different sound sources were played artificially through a loudspeaker to allow variable control of the sensory factors. Considering the availability of food odour and the actual situation at the site that met the conditions, the smell of a bakery was selected as the odour variable. Research has showed that people's preference for bakery smell is relatively consistent and ranges from moderate to high [18].
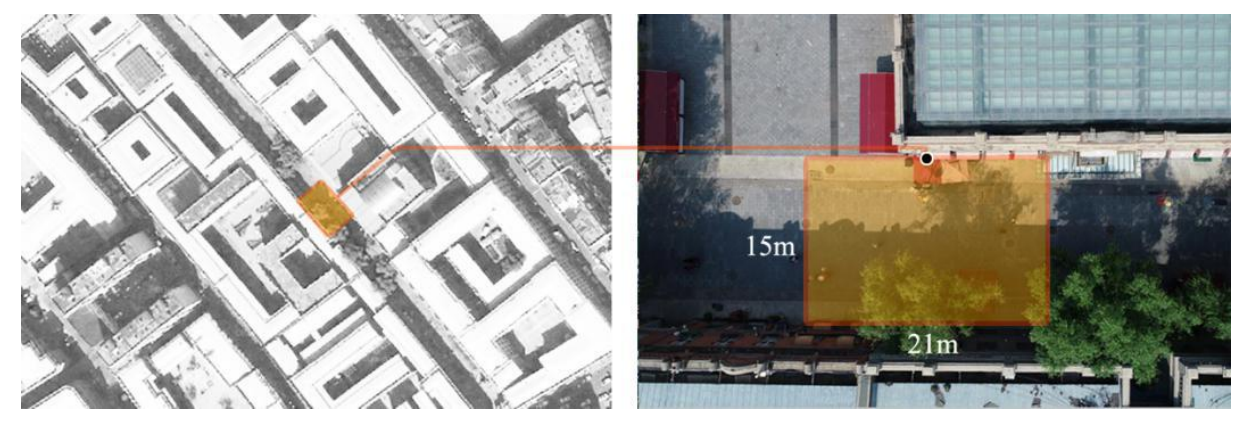

Fig. 1 The study area and scope

The bakery was located in Nansandao Street, Daowai District in the city of Harbin, China. Nansandao Street is a commercial pedestrian street, located in a historic district, where most pedestrians come to stroll without purpose. A pilot investigation showed that the proportion of men and women in the area was almost balanced; further, because (unlike in parks and squares) there are no sitting areas or recreational facilities, Nansandao Street attracts more young and middle-aged people compared to senior citizens and children. The pilot investigation also revealed that bread fresh out of the bakery's oven had a strong aroma with a wide distribution area. Baking consecutive batches released the aroma evenly. Subsequently, the odour gradually faded as the quantity of bread decreased with consumer purchases, and when there was little bread left, the odour could not be perceived. After consulting with the shopkeeper, he agreed to bake bread at a fixed time and play sound through a loudspeaker as well as inform the researcher in advance of the bread-making time. The study area is shown in Fig. 1-the bakery was located in the middle of the longer side of the area. When the smell of baked bread was present, it would cover the entire area; in its absence, the odour could not be perceived in the area.

\subsection{Sound source selection}

In this study, sounds played through a loudspeaker were used as the sound sources; therefore, artificial sounds were chosen, and their impact on people involved both positive and negative aspects. Typical sound sources of fan and music sounds in urban public open spaces were chosen. 
Cooling fans control the ambient temperature of equipment—-from construction machinery, vehicle engines, and air conditioners to electronic equipment used in daily life — and are necessary for their normal operation; thus, the sound produced by cooling fans is a typical sound source in daily life [34]. The fan sounds were selected before conducting the experiment. Fan sounds of several urban environments were selected, 30 individuals were randomly selected to evaluate the degree of annoyance of these sounds (on a 7-point scale ranging from 'not annoying' to 'annoying'). The fan sound with the highest score (more than 6) was chosen as the sound source for this experiment.

Urban public open spaces should induce a feeling of relaxation and comfort, and therefore, light music was selected. The speed of the music (beats per minutes or bpm) is an important characteristic. Studies have shown that 40-70 bpm is defined as slow speed; 85-110 bpm, medium speed; and over 120 bpm, fast speed [35]. Furthermore, music below 80 bpm was associated with negative emotions and a decrease in heart rate, whereas music above $120 \mathrm{bpm}$ was associated with positive emotions and increased heart and respiratory rates [36]. Therefore, the chosen music should not be too fast or slow, that is, it should have a medium speed. The chosen track, Annie's Wonderland by Bandari, has a speed of 100.99 bpm and a high ranking online in terms of listening pleasure.

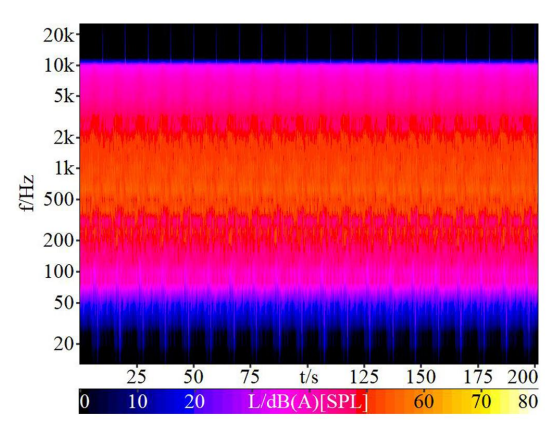

a) Frequency spectrum of fan sound (vs. time)

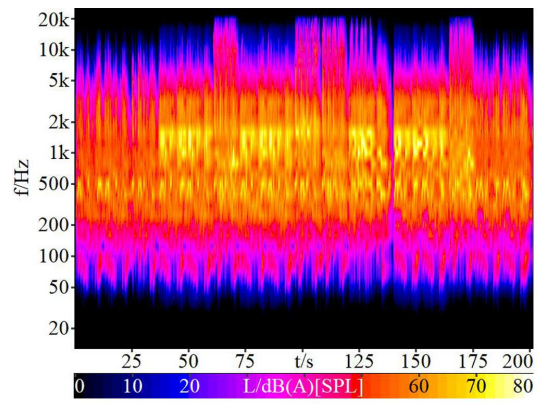

b) Frequency spectrum of music (vs. time)

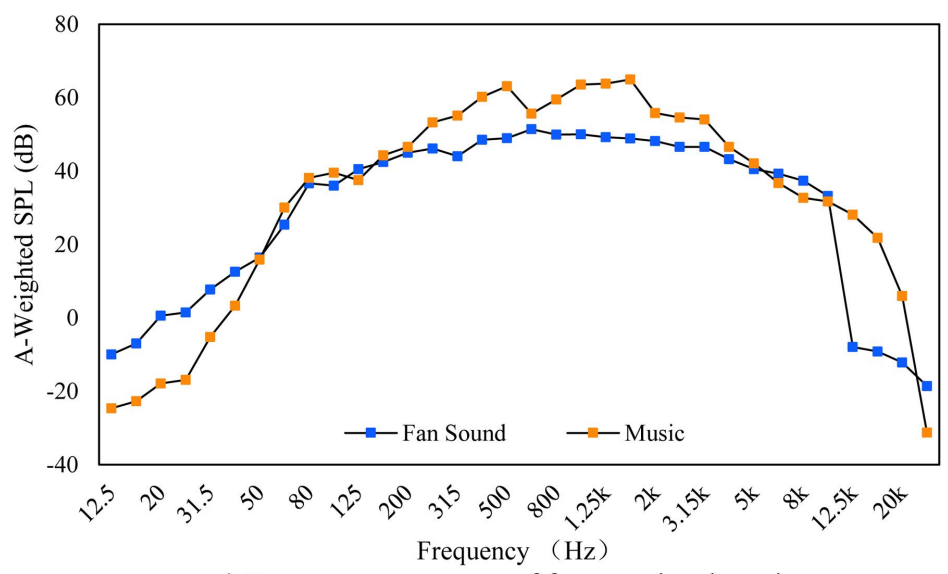

c) Frequency spectrums of fan sound and music

Fig. 2 Frequency spectrums of the experimental sounds

Therefore, the sound variables in this study were divided across three conditions: without played sound (natural 
condition), with fan sound, and with music. For playing sounds, the location of the loudspeaker should be taken into account: sound could be heard anywhere in the study area and the distance between the front of the loudspeaker and the wall or any other reflectors was at least $1.5 \mathrm{~m}$ [37]. The loudspeaker was hidden in the study area to avoid any visual impact [27]. The frequency spectrums of the played sounds in the experiment are shown in Fig. 2. The fan sound had more low-frequency components and the variability in time was not obvious; on the other hand, the music had more intermediate-frequency components and the variability in time was high.

\subsection{Objective measurement of the sensory environment}

Before conducting the experiment, the study area was meshed for later measurement and analysis, with each grid measuring $3 \mathrm{~m} \times 3 \mathrm{~m}$. In this study, changes in the odour variable were divided into those in the presence or absence of sound. Odour is an important characteristic of air quality and its concentration measurement is very complex. Therefore, odour concentration was measured through pedestrians' subjective perception. Before the experiment, a questionnaire survey of odour intensity was conducted in the study area (on a 7-point scale ranging from 'light' to 'strong'), and at least 30 questionnaires were collected in each grid. The location and average subjective intensity of the odour source are shown in Fig. 3a.
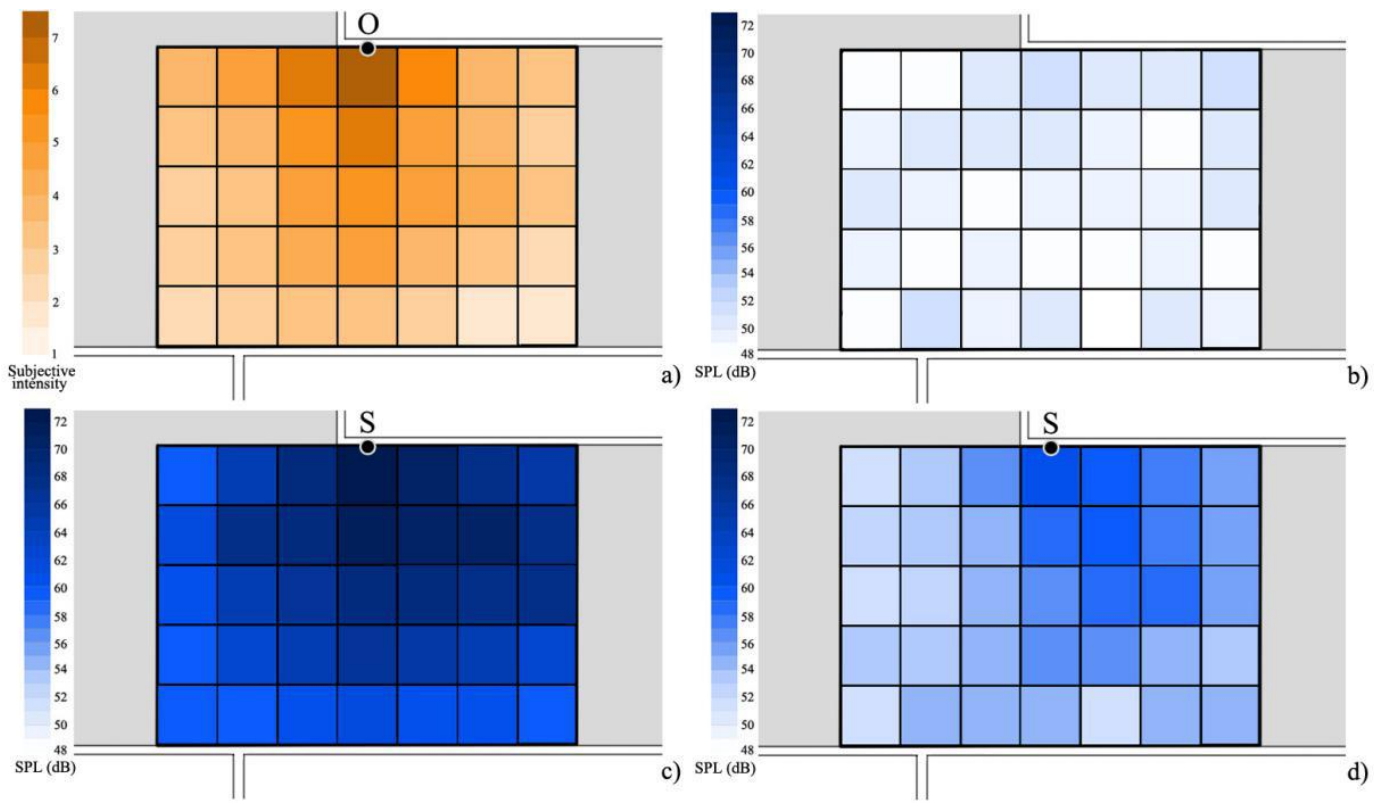

Fig. 3 Distribution of subjective intensity of odour and SPL in the case site $(\mathrm{O}=$ odour source, $\mathrm{S}=$ sound source $)$ : a) with bakery odour; b) without played sound; c) with music; and d) with fan sound.

The sound pressure levels (SPLs) of the music and fan sound corresponded to their actual SPL, and the SPLs of the 
acoustic environment before and after playing the sounds were measured. A portable four-channel high-fidelity recorder (SQuadriga III with BHS II) was used to record the sounds in each area before and after playing the sounds. The measuring points were set in the centre of each divided grid, and the recording time lasted 1 minute $[38,39]$. Subsequently, the SPL of each measuring point was analysed using HEAD ArtemiS 12.00 software. The location of the sound source and average SPL are shown in Fig. 3b, 3c, and 3d. During the experiment, the crowd density was less than $0.05 / \mathrm{m}^{2}$; therefore, the influence of a crowd on SPL could be ignored [40]. The average SPLs without played sound, with played music, and with played fan sound were 54.2, 65.2, and $54.9 \mathrm{~dB}$, respectively.

\subsection{Behavioural observation}

When there was odour or no odour, two more sounds were played, resulting in a total of six conditions. In order to avoid the influence of environmental and time factors and considering the adequacy of the crowd sample, the experiment was conducted on a sunny working day in August from 3 to $5 \mathrm{pm}$. The monthly average temperature was $17-24{ }^{\circ} \mathrm{C}$ and the relative humidity was stable. The air quality index on the day of the experiment was 20; any score below 50 means the air quality was good, and in this case there was almost no air pollution [41].

The observation of crowd behaviour included the path, speed, and duration time of the crowd. An unmanned aerial vehicle (UAV) was used to record crowd behaviour in the six conditions. In order to avoid the sound of the UAV from affecting the experiment, the flying altitude was more than $100 \mathrm{~m}$ [42]. Each video shot by the UAV lasted for 15-20 minutes, and three groups of videos were recorded for random behaviours [27]. During the experiment, sound and silence were played in a loop [43].

\subsection{Data analysis}

A total of 608 samples were collected for behavioural analysis. Different samples were used for the analyses of movement and non-movement behaviours. Table 1 shows the numbers of samples in each condition.

Table 1 Number of behavioural observation samples across conditions

\begin{tabular}{ccccc}
\hline Odour condition & Sound condition & Path & Speed & Duration time \\
\hline \multirow{3}{*}{ Without } & Without played sound & 38 & 38 & 23 \\
\cline { 2 - 5 } & Music & 38 & 38 & 24 \\
\cline { 2 - 5 } & Fan sound & 39 & 39 & 20 \\
\hline \multirow{3}{*}{ With } & Without played sound & 40 & 40 & 24 \\
\cline { 2 - 5 } & Music & 42 & 42 & 26 \\
\cline { 2 - 5 } & Fan sound & 38 & 38 & 21 \\
\cline { 2 - 4 }
\end{tabular}

In previous studies of crowd path analysis, the path was represented by a set of dots and each dot was considered to 
indicate a relatively independent process; therefore, the entire process was regarded as the collection of data between many dots [44]. In this study, a screenshot of the video sample was taken every 2 seconds, the corresponding position of the observed object on the divided grid was marked, and the dots were subsequently connected in turn to obtain each path. The crowd path scope was calculated using grid lines as the coordinate system, as shown in Fig. 4. Taking the point in the lower left corner of the grid as the origin, the abscissas corresponding to the eight longitudinal lines of the grid are $\mathrm{X}_{1}$ (value is 0 ) to $\mathrm{X}_{8}$. In addition, $\mathrm{Y}_{1}$ is the ordinate average of the intersection of all paths and $\mathrm{X}=\mathrm{X}_{1}$, that is, $\mathrm{Y}_{1}=\left(\mathrm{Y}_{11}+\right.$ $\left.\mathrm{Y}_{12}+\mathrm{Y}_{13}+\ldots .+\mathrm{Y}_{1 \mathrm{n}}\right) / \mathrm{n}$. Next, the average values of the ordinates of the intersections on each longitudinal line, $\mathrm{Y}_{1}$ to $\mathrm{Y}_{8}$, as well as the $5^{\text {th }}$ and $95^{\text {th }}$ percentiles (in meters) were calculated. The dots corresponding to the mean value and percentile were connected successively to form a smooth curve by using the spline interpolation method, allowing the scope of the crowd path to be obtained for each condition.

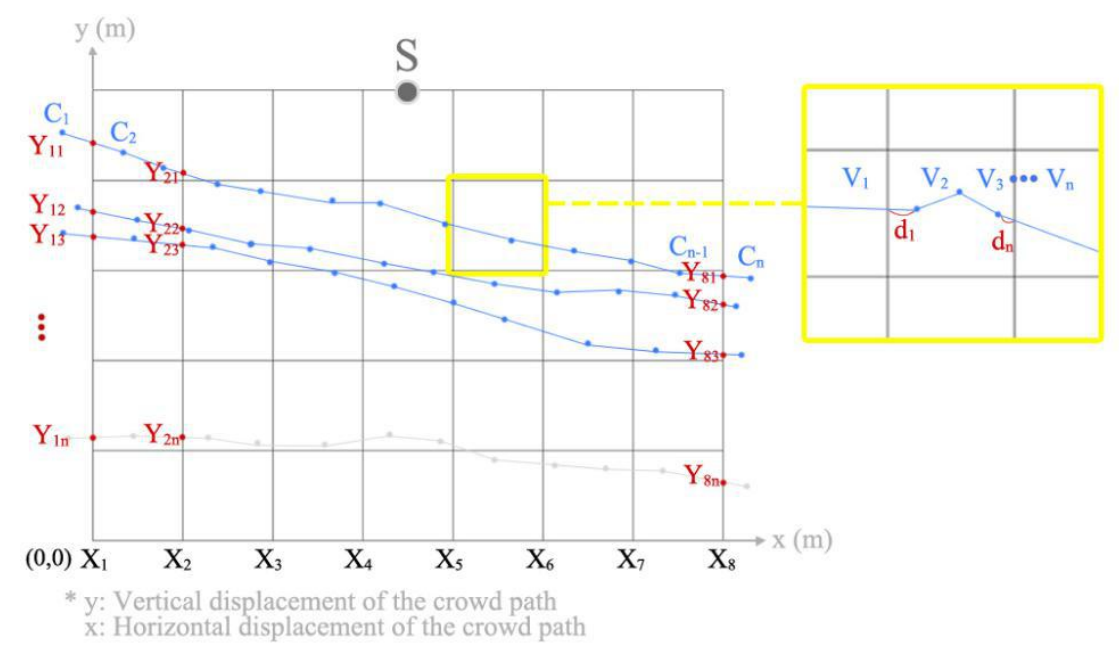

Fig. 4 Schematic diagram of the grid corresponding to the coordinates

The formula for calculating average speed was $V_{\mathrm{n}-1}=\Delta L_{\mathrm{n}} / \Delta T_{\mathrm{n}}$, where $\Delta L \mathrm{n}$ is the distance between dot $\mathrm{C}_{\mathrm{n}}$ and dot $\mathrm{C}_{\mathrm{n}-1}, \Delta T_{\mathrm{n}}$ is the time from $\operatorname{dot} \mathrm{C}_{\mathrm{n}-1}$ to $\operatorname{dot} \mathrm{C}_{\mathrm{n}}$, and $V_{\mathrm{n}-1}$ is the average speed from $\operatorname{dot} \mathrm{C}_{\mathrm{n}-1}$ to $\operatorname{dot} \mathrm{C}_{\mathrm{n}}$. The total average speed of each path was: $V=\left(V_{1}+V_{2}+V_{3} \ldots . . .+V_{\mathrm{n}-1}\right) /(\mathrm{n}-1)$.

For the speed calculation in each grid, $L_{\mathrm{g}}$ is the total distance of a path in a grid, and its formula is: $L_{\mathrm{g}}=d_{1}+\Delta T_{\mathrm{n}}\left(V_{2}\right.$ $\left.+V_{3} \ldots . . .+V_{\mathrm{n}-1}\right)+d_{\mathrm{n}}$ (see the box on the right in Fig. 4). $\mathrm{T}_{\mathrm{g}}$ is the total time of a path in a grid and its formula is: $T_{\mathrm{g}}$ $=\Delta T_{\mathrm{n}}(\mathrm{n}-2)+d_{1} / V_{1}+d_{\mathrm{n}} / V_{\mathrm{n}}$. Thus, the speed in each grid is $V_{\mathrm{g}}=L_{\mathrm{g}} / T_{\mathrm{g}}$. 


\section{Results}

\subsection{Effects of sound and food odour on crowd path}

The original crowd path distributions under the six conditions are shown in Fig. 5. When there was no bakery odour, the crowd path distribution was even when sound was not played. Compared with the no-sound condition, the crowd paths appeared to be more concentrated when playing music and tended to be farther away from the sound source when playing fan sound. When there was bakery odour, the paths were denser compared to those in the condition with no sensory sources; after playing music and fan sound, the paths were closer to the sensory source.
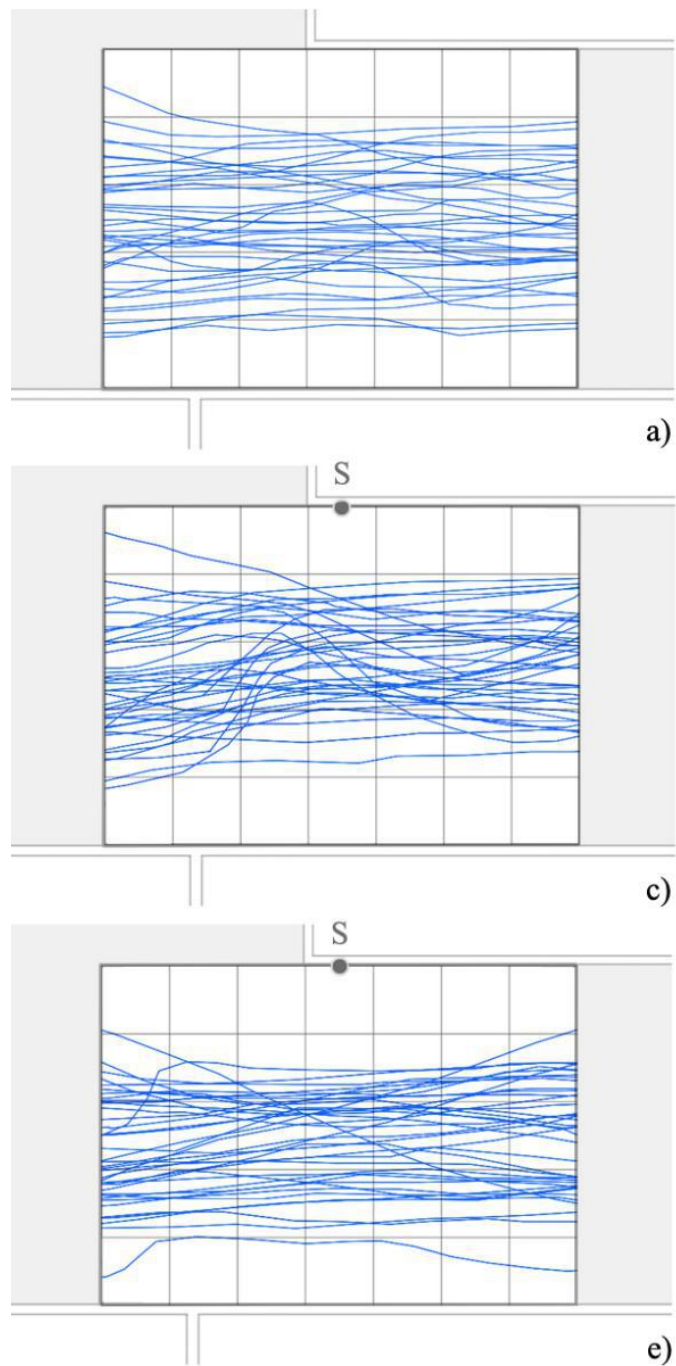

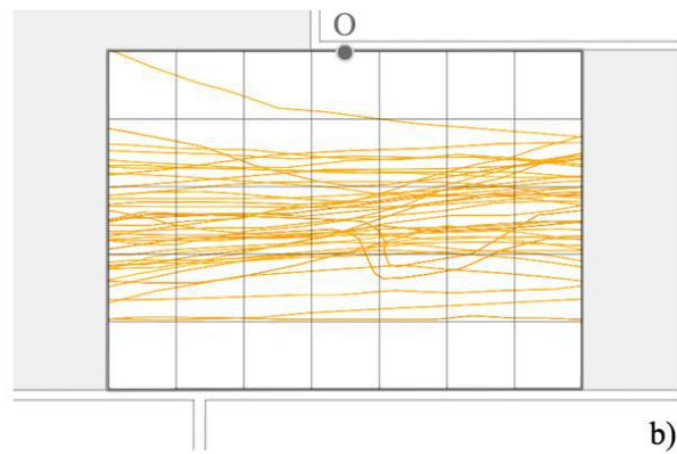

b)

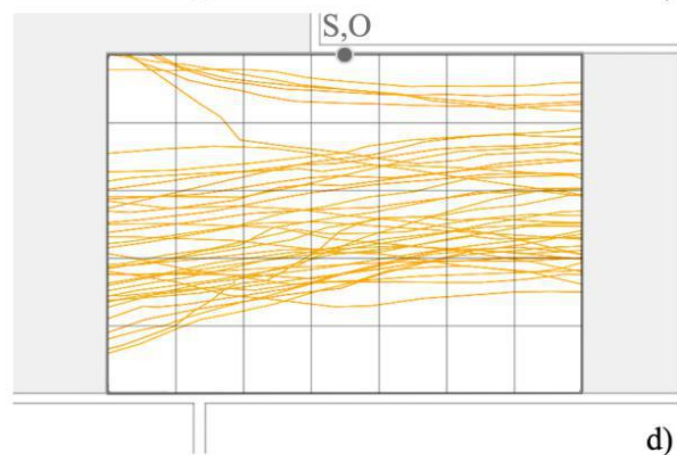

d)

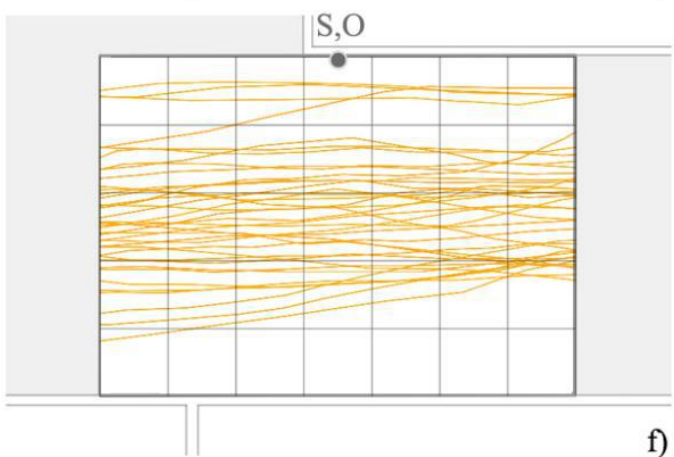

Fig. 5 Distribution of crowd paths in the case site under the combination of bakery odour and sounds $(\mathrm{S}=$ sound source, $\mathrm{O}=$ odour source): a) without odour and played sound; b) with odour and without played sound; c) without odour and with music; d) with odour and music; e) without odour and with fan sound; and f) with odour and fan sound 
The scopes of the crowd path under the six conditions are shown in Fig. 6. The blue block on the left represents the sound pressure level distribution, the orange block represents the subjective intensity distribution, and the superposition of the two colour blocks represents the superposition of sound and odour. Further, the lines connected by the mean values were distributed in the middle of the grid. When there was no odour, the scopes with the sounds were more concentrated than those in the case of no sound and odour. When music was present, the lower boundary of the scope had a tendency to move upward; when fan sound was present, the upper boundary of the scope had a downward trend. One possible reason is that the music had a high SPL and wide range of influence, which could have held a certain appeal for the crowd. However, the SPL near the sound source was very high and the average SPL of the grid where the loudspeaker was located was $72.5 \mathrm{~dB}$ in order that people could not approach it. For fan sound, its SPL and frequency were low; people near the sound source would avoid it whereas those who were far away from the sound source may have had low recognition of it, and therefore, it had little impact on the crowd path. With the bakery odour, the scope was wider, which was reflected in the upward trend of both the upper and lower boundaries of the crowd path. The upward trend of the upper boundary was the most prominent in the condition with music followed by the condition with fan sound. This finding shows that in the conditions with the bakery odour, the crowd would approach the odour source and both positive and negative sounds could make this trend more obvious. 

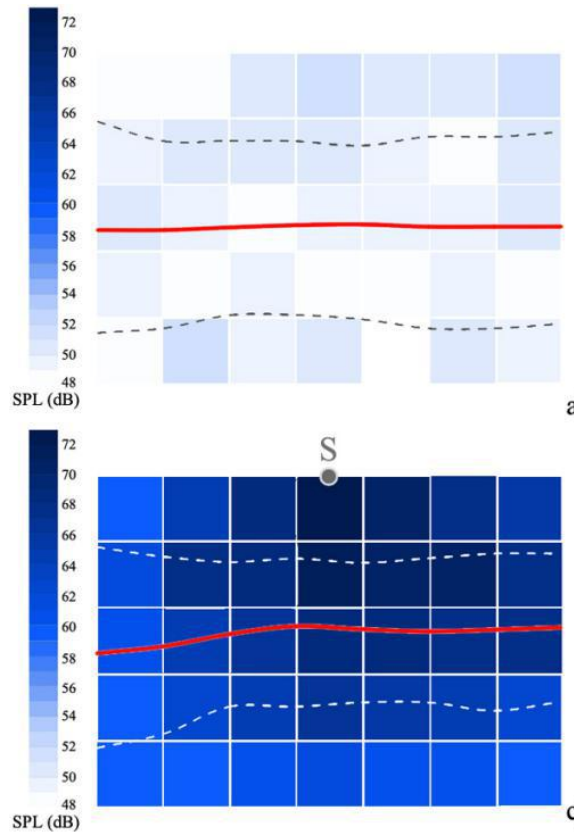

a)

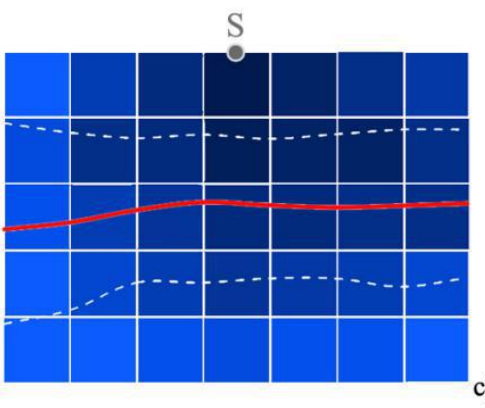

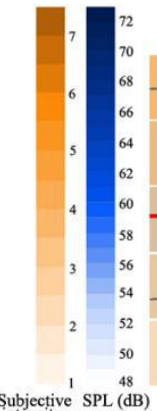
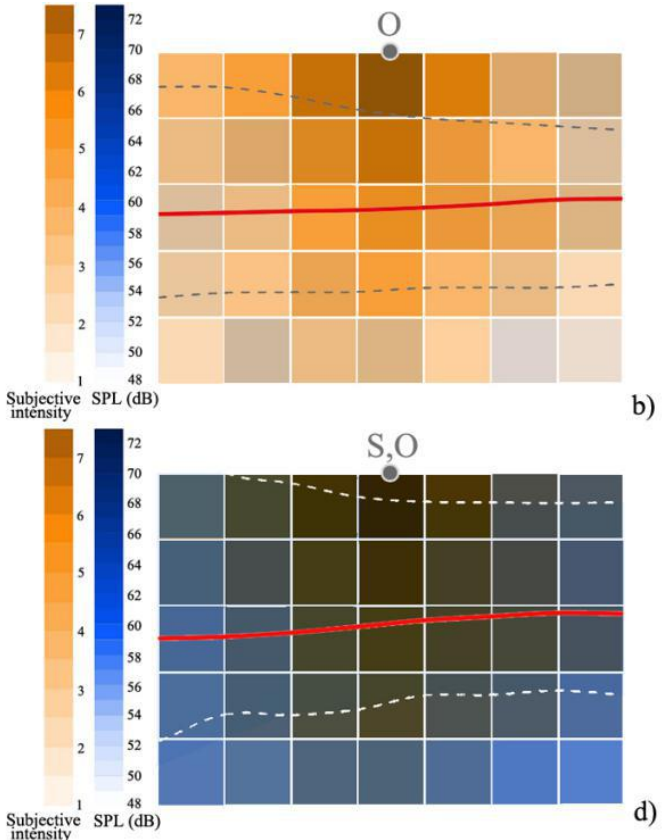

)
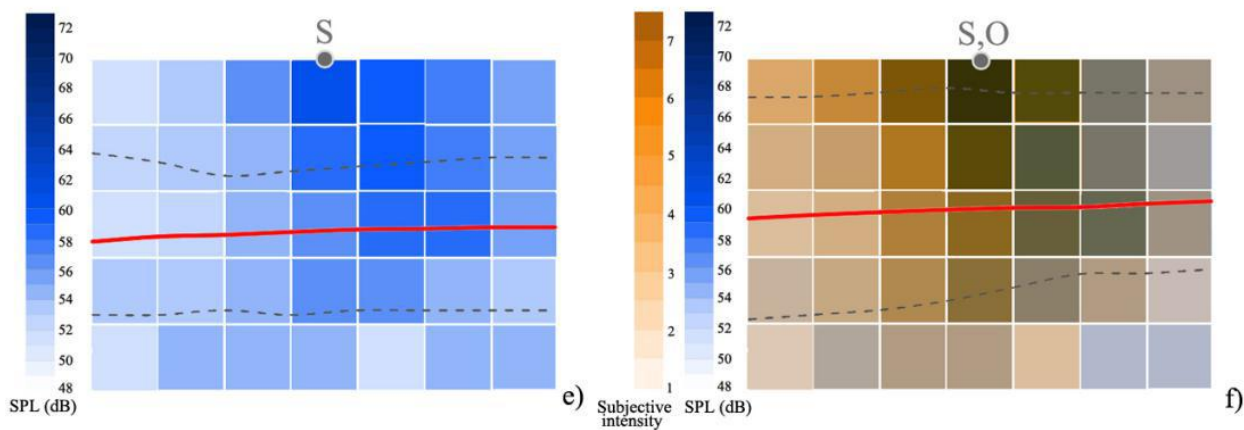

Fig. 6 Scope of crowd paths in the case site under the combination of bakery odour and sounds $(\mathrm{S}=$ sound source, $\mathrm{O}=$ odour source): a) without odour and played sound; b) with odour and without played sound; c) without odour and with music; d) with odour and music; e) without odour and with fan sound; and f) with odour and fan sound

The path of each person in the study area was composed of different dots, which could be regarded as a continuous and complete process. Taking the sound and odour conditions as the independent variables, the all-factor model was used to apply a repeated measurement ANOVA of the ordinate value $y$ at the intersections of the paths and longitudinal lines of the grid. The results, which are shown in Table 2, demonstrate that there were significant differences in the ordinate value $\mathrm{y}$ and the sound and odour conditions $(\mathrm{p}<0.05)$. Further, the interaction effect between the sound and odour conditions was significant $(p=0.000<0.01)$, and the results of Mauchly's test of sphericity showed that the data did not obey the spherical hypothesis $(\mathrm{p}=0.000<0.01)$, indicating that the results of each repeated measurement were related.

Table 2 Repeated measurement ANOVA of the ordinate value $y$ at the intersections of the paths and longitudinal lines of the grid 


\begin{tabular}{|c|c|c|c|c|c|c|}
\hline \multicolumn{2}{|c|}{ Effect } & Value & $\mathrm{F}$ & $\begin{array}{l}\text { Hypothes } \\
\text { is } \mathrm{df}\end{array}$ & Error df & Sig. \\
\hline \multirow{4}{*}{$\mathrm{y}$} & Pillai's trace & .218 & 8.042 & 7.000 & 202.000 & .000 \\
\hline & Wilks' lambda & .782 & 8.042 & 7.000 & 202.000 & .000 \\
\hline & Hotelling's trace & .279 & 8.042 & 7.000 & 202.000 & .000 \\
\hline & Roy's largest root & .279 & 8.042 & 7.000 & 202.000 & .000 \\
\hline \multirow{4}{*}{$y *$ Sound } & Pillai's trace & .121 & 1.863 & 14.000 & 406.000 & .029 \\
\hline & Wilks' lambda & .880 & 1.901 & 14.000 & 404.000 & .025 \\
\hline & Hotelling's trace & .135 & 1.940 & 14.000 & 402.000 & .021 \\
\hline & Roy's largest root & .127 & 3.683 & 7.000 & 203.000 & .001 \\
\hline \multirow{4}{*}{$\mathrm{y} *$ Odour } & Pillai's trace & .100 & 3.189 & 7.000 & 202.000 & .003 \\
\hline & Wilks' lambda & .900 & 3.189 & 7.000 & 202.000 & .003 \\
\hline & Hotelling's trace & .111 & 3.189 & 7.000 & 202.000 & .003 \\
\hline & Roy's largest root & .111 & 3.189 & 7.000 & 202.000 & .003 \\
\hline \multirow{4}{*}{$\mathrm{y} *$ Sound $*$ Odour } & Pillai's trace & .193 & 3.103 & 14.000 & 406.000 & .000 \\
\hline & Wilks' lambda & .811 & 3.181 & 14.000 & 404.000 & .000 \\
\hline & Hotelling's trace & .227 & 3.258 & 14.000 & 402.000 & .000 \\
\hline & Roy's largest root & .198 & 5.750 & 7.000 & 203.000 & .000 \\
\hline
\end{tabular}

Fig. 7 shows the estimated marginal mean of the ordinate value y under the presence or absence of odour, type of sound, and interaction effect between the two. The higher the value, the closer the crowd was to the sound or odour source. Fig. 7a shows the estimated marginal mean of the ordinate value y only under the influence of sound. The values of $Y_{1}$ and $Y_{2}$ showed the same trend under the influence of the sound conditions, while the values of $Y_{3}$ to $Y_{8}$ showed that music had an attractive effect on the crowd. This is consistent with the results of a previous study in which the crowd samples had clear purpose when walking [27]. The results of our study showed that crowds who do not have a clear purpose when walking also have a tendency to move towards music. The changing trend of the crowd path when playing fan sound was similar to that when there was no sound source. Fig. $7 \mathrm{~b}$ shows the estimated marginal mean value of the ordinate value y only under the influence of odour, and the values in the case with the bakery odour were higher than those in the case without odour, indicating that the bakery odour attracted people to a certain extent. Fig. 7c shows the estimated marginal mean of the ordinate value y under the interaction effect of sound and odour. In the absence of the bakery odour, music attracted the crowd as compared with when no sounds were played; the attractive effect was stronger the closer people were to the sound source. The fan sound would repel the crowd away from the sound source, and its values of $Y_{6}, Y_{7}$, and $Y_{8}$ were similar to those when there was no sound. For the case with the bakery odour, music induced the strongest attraction in the crowd compared with no played sound, mainly reflected in the values of $Y_{4}$, $\mathrm{Y}_{5}$, and $\mathrm{Y}_{6}$; the maximum approach was about $0.64 \mathrm{~m}$ compared with the no-odour condition. Fan sound also made the crowd approach the sound source, mainly reflected in the values of $\mathrm{Y}_{4}$ and $\mathrm{Y}_{5}$; the maximum approach was about $0.93 \mathrm{~m}$ compared with the no-odour condition. One possible reason is that when there was a certain odour in the area, people could not immediately distinguish the location of the odour source, and the emergence of sound attracted the attention of the crowd, thereby clarifying the location of the odour source and resulting in a clearer tendency. The results also showed 
that the trend of the paths was gradually tilted and rising from $Y_{1}$ to $Y_{8}$, which might be because of the fact that there was a doorway about $10 \mathrm{~m}$ to the left of $\mathrm{X}_{1}$, and there was a tilting trend when people passed through it.
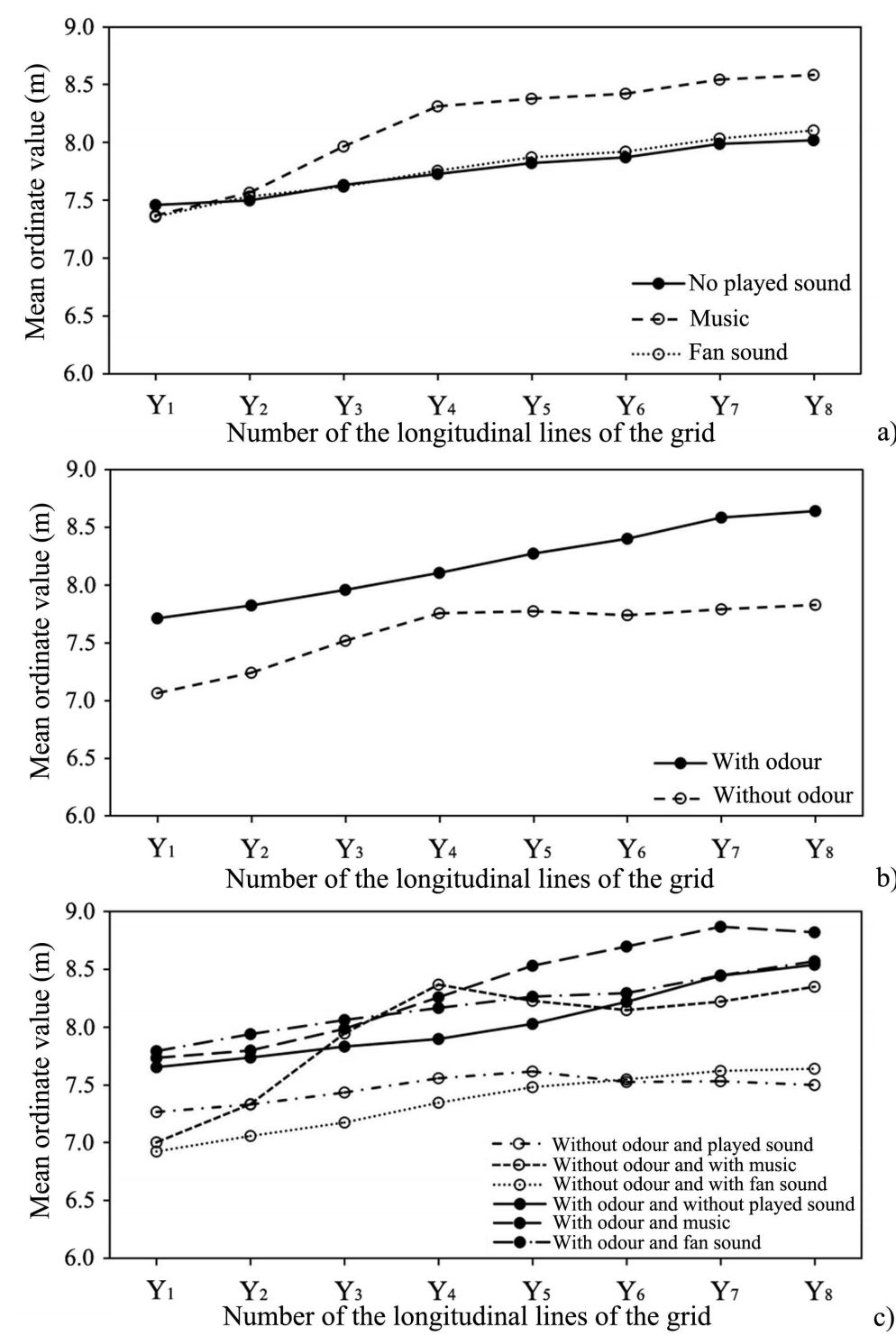

Fig. 7 Estimated marginal mean value of the ordinate value $y$ at the intersections of the paths and longitudinal lines of the grid: a) under the sound condition; b) under the odour condition; and c) under the interaction of sound and odour

\subsection{Effects of sounds and food odour on crowd speed}

A multi-factor ANOVA was conducted to test the differences in average speed between the subgroups divided by the two main variables; the results are shown in Table 3. The effects of sound and odour on average speed were significant ( $p$ $<0.05)$, while the interaction effect between sound and odour was not significant $(p=0.953>0.05)$. This means that under different sound conditions, the trends of change in crowd speed in conditions with or without odour were unchanged; similarly, under conditions with and without odour, the trends of change in crowd speed under the influences 
of different sound conditions were also unchanged. This indicated that the influences of sound type and the presence or absence of odour on crowd speed were relatively independent. This study included both positive and negative sounds; however, the odour was a positive one, and different types of odours may lead to different results.

Table 3 Multi-factor ANOVA of average speed under the influence of sound and bakery odour

\begin{tabular}{cccccc}
\hline Source & Type III sum of squares & df & Mean square & F & Sig. \\
\hline Corrected model & $62.888^{\mathrm{a}}$ & 5 & 12.578 & 7.976 & .000 \\
Intercept & 6353.643 & 1 & 6353.643 & 4028.895 & .000 \\
Sound & 56.912 & 2 & 28.456 & 18.044 & .000 \\
Odour & 6.880 & 1 & 6.880 & 4.363 & .038 \\
Sound * Odour & .151 & 2 & .075 & .048 & .953 \\
\hline
\end{tabular}

The estimated marginal mean of the total average speed was $1.11 \mathrm{~m} / \mathrm{s}$ and the estimated marginal means of the average speeds under different conditions are shown in Fig. 8. The Scheffe method was used for post-hoc comparisons of the average speeds under different conditions when the influencing factors were significant. Fig. 8a shows the average crowd speed only under the influence of sound. The results showed that compared with no played sound, music significantly reduced crowd speed $(\mathrm{p}=0.046<0.05)$, which is in line with previous studies [27,29]. Fan sound significantly increased crowd speed $(p=0.003<0.01)$ and there was a significant difference between music and fan sound $(p=0.000<0.01)$. Fig. $8 \mathrm{~b}$ shows the average crowd speed only under the influence of odour; crowd speed was significantly higher with odour than without odour, and because the experiment was conducted in the afternoon, the smell of food may have made people hungry and walk faster. Fig. $8 \mathrm{c}$ shows the average crowd speed under the influence of both sound and odour; it was the lowest when there was music and no odour, and the highest when there was fan sound and odour, with a difference of about $0.34 \mathrm{~m} / \mathrm{s}$. 

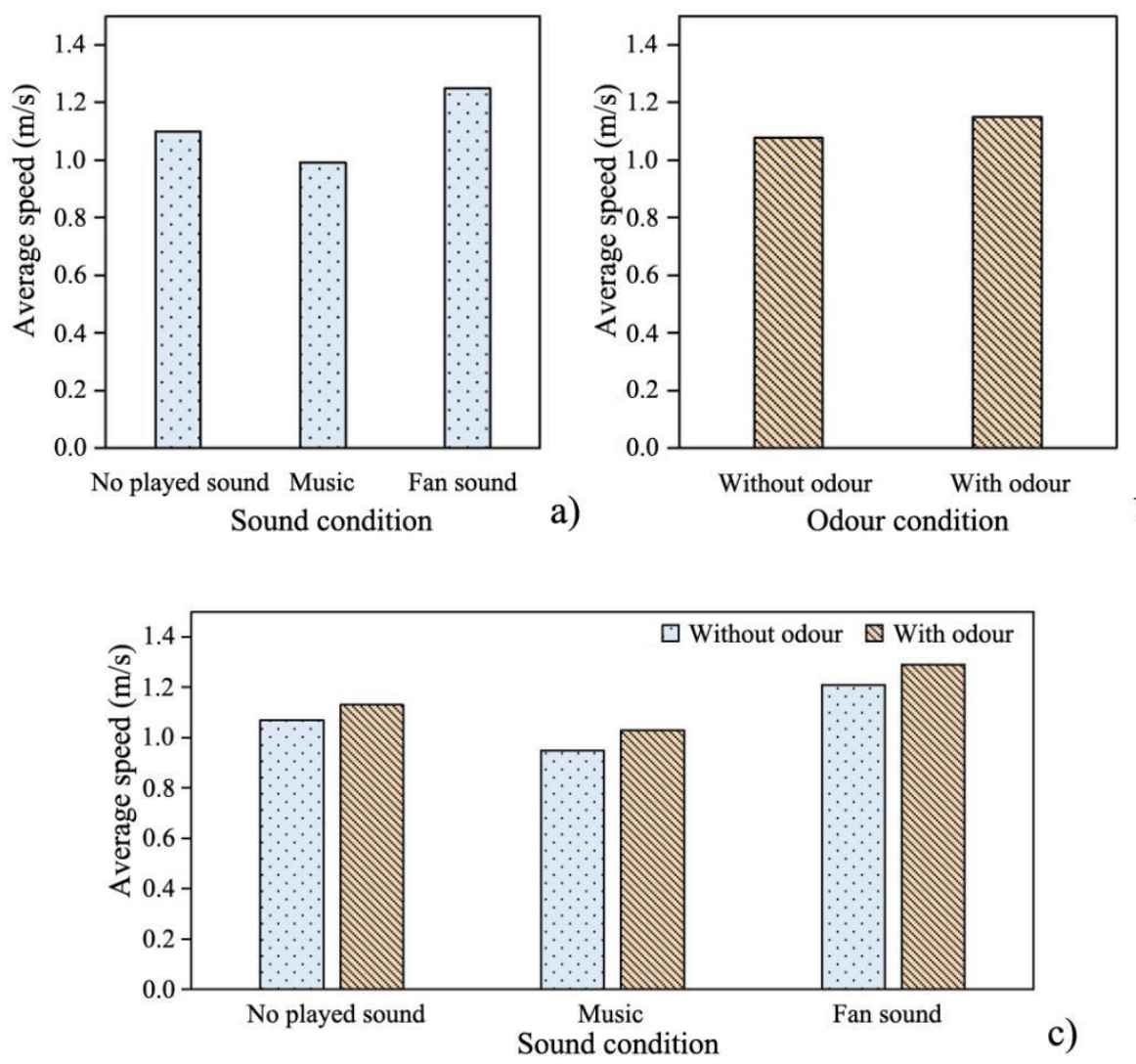

Fig. 8 Average crowd speeds in the case site under the combination of sounds and bakery odour: a) under the sound condition; b) under the odour condition; and c) under the interaction of sound and odour

As shown in Fig. 9, the grids are numbered from top to bottom. Further, the grids of the first row are marked $\mathrm{G}_{11}$ to $\mathrm{G}_{17}$ from left to right, and the grids of the fifth row are marked $\mathrm{G}_{51}$ to $\mathrm{G}_{57}$ from left to right. The average speed in each grid was calculated. In the case of no bakery odour, the average speed distribution was even in the absence of sound. In the case of music, the average speed decreased gradually as the distance from the sound source decreased; however, the average speed at $\mathrm{G}_{13}$ near the sound source was higher than that at $\mathrm{G}_{12}$, and their average speeds were $0.96 \mathrm{~m} / \mathrm{s}$ and 0.77 $\mathrm{m} / \mathrm{s}$, respectively. One possible reason is that the music SPL there was high, which was insufferable for people, thereby hastening their pace. In the case of fan sound, the average speeds at $G_{21}$ to $G_{27}$, which were closer to the sound source, were higher than those in the central region, and the highest average speed was $1.59 \mathrm{~m} / \mathrm{s}$ at $\mathrm{G}_{24}$ and $\mathrm{G}_{25}$. In the case of the bakery odour, the average speed distribution decreased as proximity to the sensory sources increased when there was no sound and with music. In the case of fan sound, the speed was higher near the sound and odour sources. The average speed was about $1.4 \mathrm{~m} / \mathrm{s}$ and the average velocity of the other grids decreased gradually the closer the sensory sources were. In the six conditions, there was a trend wherein the average speed of individuals walking at the edge of the street 
was higher than that of individuals in the middle of the street.
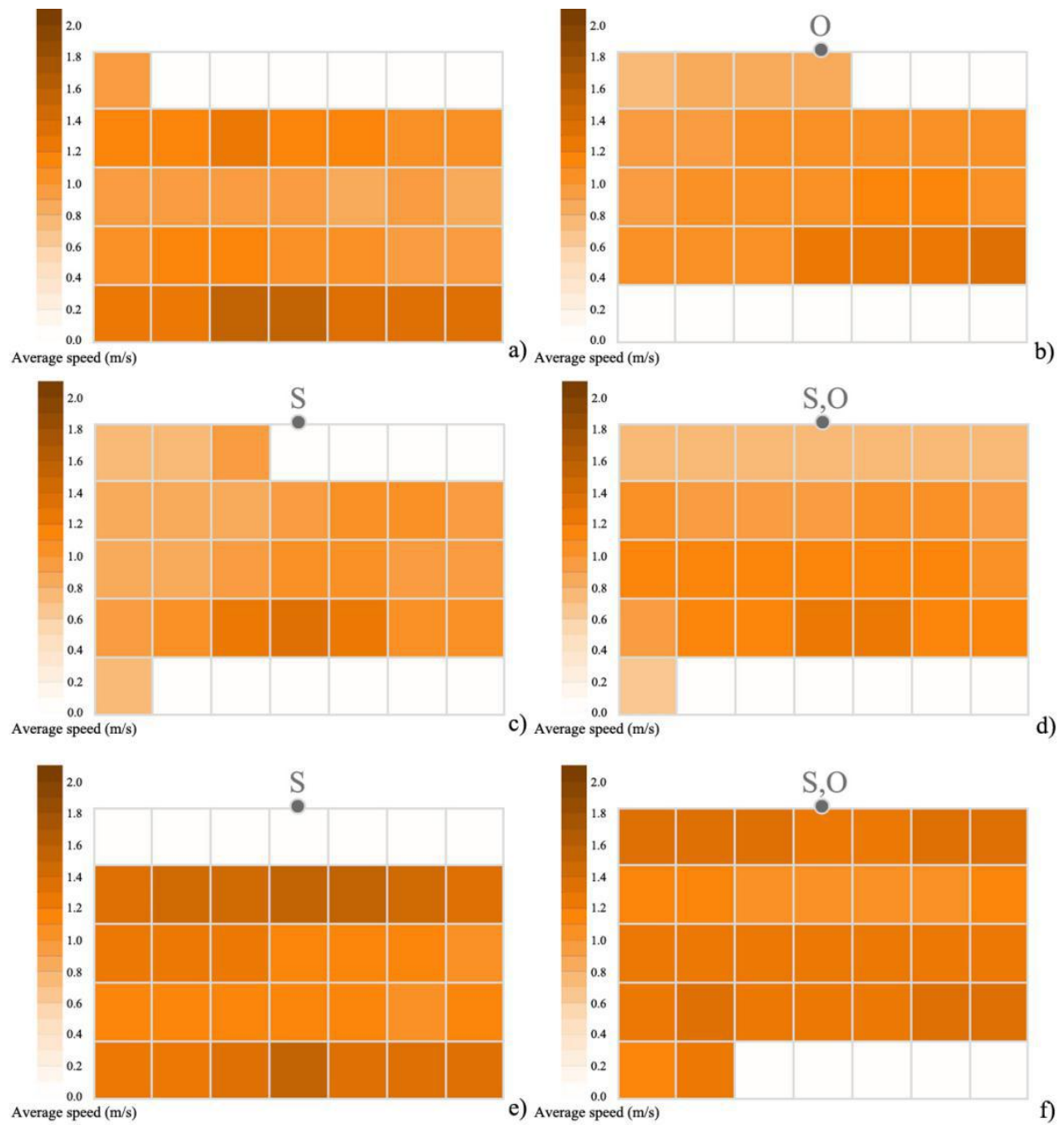

Fig. 9 Distribution of average speeds in the case site under the combination of bakery odour and sounds $(\mathrm{S}=$ sound source, $\mathrm{O}$ = odour source): a) without odour and played sound; b) with odour and without played sound; c) without odour and with music; d) with odour and music; e) without odour and with fan sound; and f) with odour and fan sound

\subsection{Effects of sounds and food odour on crowd duration time}

A multi-factor ANOVA was conducted to test differences in average duration time between the subgroups divided by the two main variables. The results, which are shown in Table 4, demonstrate that the effects of sound and odour on average speed were significant $(\mathrm{p}<0.05)$, while the interaction effect between sound and odour was not significant $(\mathrm{p}=$ $0.824>0.05)$. This means that under different sound conditions, the trends of change in crowd duration time with or without odour were unchanged; similarly, in the with and without odour conditions, the trends of change in crowd duration time under the influences of different sound conditions were unaffected. This indicated that the influences of sound type and the presence or absence of odour on duration time were relatively independent. A previous study in 
indoor shopping malls showed that the tempo of music and presence of citrus odour had an interactive effect on people's duration time; the combination of odour and fast-tempo music increased the length of duration time, while the combination of odour and slow-tempo music shortened the duration time [33]. In our study, the sound variable was the type of sound, and different combinations of sound and odour with different characteristics may have different effects.

Table 4 Multi-factor ANOVA of average duration time under the influence of sound and bakery odour

\begin{tabular}{cccccc}
\hline Source & Type III sum of squares & df & Mean square & F & Sig. \\
\hline Corrected model & $160064.204^{\mathrm{a}}$ & 5 & 32012.841 & 11.809 & .000 \\
Intercept & 2233571.986 & 1 & 2233571.986 & 823.950 & .000 \\
Sound & 145726.998 & 2 & 72863.499 & 26.879 & .000 \\
Odour & 11332.820 & 1 & 11332.820 & 4.181 & .043 \\
Sound * Odour & 1049.275 & 2 & 524.638 & .194 & .824 \\
\hline
\end{tabular}

The estimated marginal mean of the total average duration time was $127.71 \mathrm{~s}$, and the estimated marginal means of average duration times under the different conditions are shown in Fig. 10. The Scheffe method was used to conduct post-hoc comparisons for average duration times under the different conditions when the influencing factors were significant. Fig. 10a shows the average duration time of the crowd only under the influence of sound. The results showed that compared with no played sound, music significantly increased crowd duration time $(p=0.003<0.05)$ by about $30 \mathrm{~s}$, which is similar to the finding of a previous study [24]. Fan sound significantly decreased crowd duration time $(\mathrm{p}=$ $0.001<0.01)$ by about $40 \mathrm{~s}$, and there was a significant difference between music and fan sound $(\mathrm{p}=0.000<0.01)$. Fig. $10 \mathrm{~b}$ shows the average duration time of the crowd only under the influence of odour; the duration time of the crowd with odour was significantly longer than that without odour $(p=0.043<0.05)$ by about 20 s. Fig. 10c shows the average duration time of the crowd under the influence of both sound and odour; it was the shortest when there was fan sound and no odour, and the longest when there was music and odour, with a difference of about $100 \mathrm{~s}$. 

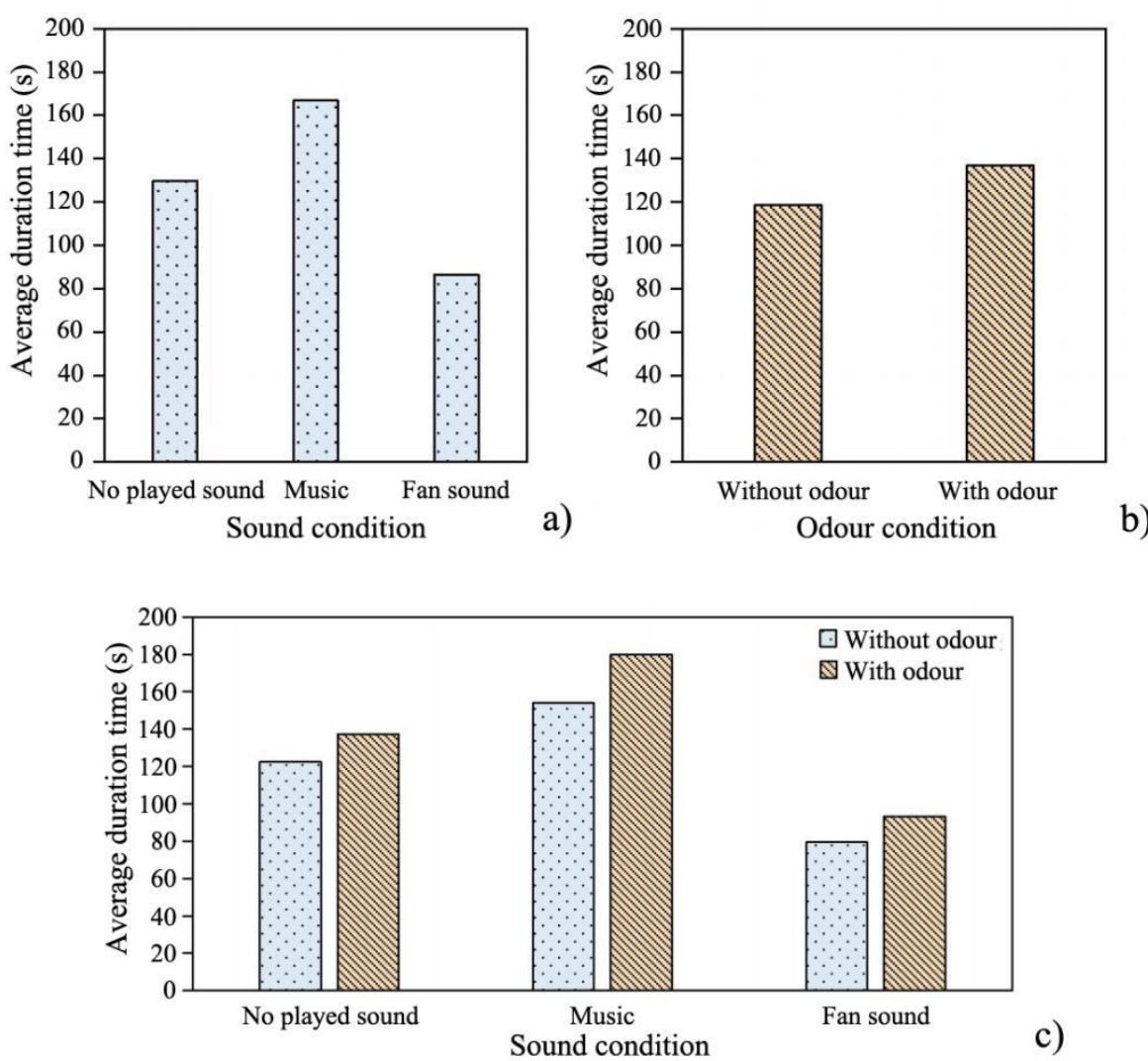

c)

Fig. 10 Average crowd duration times in the case site under the combination of sounds and bakery odour: a) under the sound condition; b) under the odour condition; and c) under the interaction of sound and odour

\section{Discussions}

The movement and non-movement behaviours in the experiment were relatively independent. For movement behaviour, path and speed were analysed using the same set of samples, and the correlations between path and speed under six conditions were examined. Table 5 shows the correlation between the average value of ordinate value $y$ at the intersections of the paths and longitudinal lines of the grid of each individual path and the average speed of each individual path. The results showed that for the six conditions, only the path under the condition of without odour and with music had a significant correlation with speed; this is reflected in the overall trend that the greater the proximity to the sound source, the slower the crowd speed, which also indicates that music attracts people and slows them down. This trend was also seen under the condition with odour and music; however, it was not significant. A possible reason is that the experiment was conducted in the afternoon, the food odour might stimulate a feeling of hunger and the music may have drawn people's attention to the bakery and made them approach it unconsciously; however, they may have passed through quickly because of not wanting to make a purchase. Therefore, their combined effects led to no significant 
correlation. Regardless of the presence of the odour, there was no significant correlation between path and speed without played sound or with fan sound, which indicated that the effect of other factors was weaker than that of music.

Table 5 Correlation between average path and average speed

\begin{tabular}{cccc}
\hline Odour condition & Sound condition & Correlation coefficient & Sig \\
\hline \multirow{2}{*}{ Without } & No played sound & .228 & .202 \\
& Music & $-.455^{* *}$ & $\mathbf{. 0 0 6}$ \\
& Fan sound & .276 & .109 \\
& No played sound & .188 & .271 \\
With & Music & -.183 & .258 \\
& Fan sound & -.127 & .467 \\
\hline
\end{tabular}

The study findings have implications for policy and programs to encourage the usage of public open spaces in cities, which are essential to the well-being of citizens. For instance, when urban spaces need to control the flow of people for urban design and planning purposes, the introduction of certain odours or sounds can change the behavioural trend of a crowd, and the superposition of specific sound and odour can strengthen the effect. Moreover, different sound or odour stimuli in the environment may have different effects on crowd behaviour; thus, considering these sensory factors can more accurately predict crowd behaviour in existing environments or urban space design. Furthermore, when there is a negative sound or odour source in an urban environment, the introduction of a particular odour or sound can reduce the negative impact of existing sensory sources on crowd behaviour. The analytical methods of the research can be used in studies of different combinations of sounds and odours, such as pollution or plant odour, to guide the design of urban function partitions, the use of landscaping plants, and government decision-making.

This research could be expanded in a number of directions. The experiment was conducted in the afternoon, and the physical condition and psychological perception of crowds vary across different times of the day. In addition, people's hunger may have affected the present results; therefore, similar future research should be conducted at other times of the day. Furthermore, future studies should also consider environmental factors such as weather, which may affect experimental results.

\section{Conclusions}

This study investigated the effects of sounds and food odour on crowd behaviour in a pedestrian street. To that end, a covert behavioural observation experiment was conducted at an urban commercial pedestrian street.

The present results show that playing music in the absence of odour attracted the crowd to the sound source, made crowd paths more concentrated, and tended to move the lower boundary of the crowd path scope upward. When playing fan sound, the crowd paths tended to be far away from the sensory sources and the upper boundary of the crowd path 
scope tended to move downward; however, the effect of fan sound was not as significant as that of music. There was an interaction effect between sound and odour: people would approach the sensory sources in the presence of the bakery odour. When playing a sound, whether positive or negative, this trend would be more significant, wherein the effect of music was stronger than that of fan sound.

Compared with the conditions where sound was not played, music significantly reduced crowd speed, and the closer a person was to the sound source, the lower their speed. Fan sound significantly increased crowd speed, and the closer a person was to the sound source, the higher their speed. Crowd speed was significantly higher in the presence, rather than absence, of bakery odour; further, the average speed decreased gradually with greater proximity to the sensory sources. However, the interaction effect between sound and odour on crowd speed was not significant. The average speed of people walking on the edge of the street was higher than that of people in the middle of the street.

Music and the bakery odour significantly increased crowd duration time, whereas fan sound did not. In addition, the interaction between sound and odour did not affect crowd duration time.

\section{Funding Source}

The work was supported by the National Natural Science Foundation of China [grant number 51778169].

\section{References}

[1] Zhou, B. (2005). The historical evolution of urban public space. (Doctoral dissertation). Sichuan University.

[2] Kang, J. (2006). Urban sound environment. Boca Raton, FL: CRC Press.

[3] Ye, M.L. (2009). Five senses applied in landscape design. (Doctoral dissertation). Tianjin University.

[4] Xiao, J., Tait, M., \& Kang, J. (2018). A perceptual model of smellscape pleasantness. Cities, 76, 105-115.

[5] Spence, C. (2004). The handbook of multisensory processes. Cambridge, MA: MIT Press.

[6] Carles, J., Bernáldez, F., \& Lucio, J. D. (1992). Audio-visual interactions and soundscape preferences. Landscape Research, 17(2), 52-56.

[7] Viollon, S. (2003). Two examples of audio-visual interactions in an urban context. Acta Acust Acust, 89, S58.

[8] Maffei, L., Iachini, T., Masullo, M., Aletta, F., Sorrentino, F., Senese, V. P., \& Ruotolo, F. (2013). The effects of vision-related aspects on noise perception of wind turbines in quiet areas. International Journal of Environmental Research and Public Health, 10(5), 1681-1697. 
[9] Lindquist, M., Lange, E., \& Kang, J. (2016). From 3D landscape visualization to environmental simulation: The contribution of sound to the perception of virtual environments. Landscape and Urban Planning, 148, 216-231.

[10] Mace, B. L., Bell, P. A., Loomis, R. J., \& Haas, G. E. (2003). Source attribution of helicopter noise in pristine national park landscapes. Journal of Park and Recreation Administration, 21, 97-119.

[11] Ma, H., \& Nie, W. (2014, October). Influence of visual factors on noise annoyance evaluation caused by road traffic noise in indoor environment. In INTER-NOISE and NOISE-CON Congress and Conference Proceedings (Vol. 249, No. 1, pp. 6308-6315). Institute of Noise Control Engineering.

[12] Gottfried, J. A., \& Dolan, R. J. (2003). The nose smells what the eye sees: Crossmodal visual facilitation of human olfactory perception. Neuron, 39(2), 375-386.

[13] Jadauji, J. B., Djordjevic, J., Lundström, J. N., \& Pack, C. C. (2012). Modulation of olfactory perception by visual cortex stimulation. Journal of Neuroscience, 32(9), 3095-3100.

[14] Michael, G. A., Jacquot, L., Millot, J. L., \& Brand, G. (2003). Ambient odors modulate visual attentional capture. Neuroscience Letters. 352(3), 221-225.

[15] Robinson, A. K., Reinhard, J., \& Mattingley, J. B. (2015). Olfaction modulates early neural responses to matching visual objects. Journal of Cognitive Neuroscience, 27(4), 832-841.

[16] Seo, H. S., Roidl, E., Müller, F., \& Negoias, S. (2010). Odors enhance visual attention to congruent objects. Appetite, 54(3), 544-549.

[17] Jiang, L., Masullo, M., \& Maffei, L. (2016). Effect of odour on multisensory environmental evaluations of road traffic. Environmental Impact Assessment Review, 60, 126-133.

[18] Ba, M., \& Kang, J. (2019a). A laboratory study of the sound-odour interaction in urban environments. Building and Environment, 147, 314-326.

[19] Ba, M., \& Kang, J. (2019b). Effect of a fragrant tree on the perception of traffic noise. Building and Environment, $156,147-155$.

[20] Meng, Q., \& Kang, J. (2016). Effect of sound-related activities on human behaviours and acoustic comfort in urban open spaces. Science of the total environment, 573, 481-493.

[21] Jia, S.Q. (2012). Crowd behavior in soundscape. (Doctoral dissertation). Harbin Institute of Technology.

[22] Yuan, W., \& Tan, K. H. (2011). A model for simulation of crowd behaviour in the evacuation from a smoke-filled compartment. Physica A: Statistical Mechanics and its Applications, 390(23-24), 4210-4218.

[23] Xie, H., Kang, J., \& Mills, G. H. (2013). Behavior observation of major noise sources in critical care wards. Journal 
of critical care, 28(6), 1109-e5.

[24] Lepore, F., Aletta, F., Astolfi, A., \& Kang, J. (2016, August). A preliminary investigation about the influence of soundscapes on people's behaviour in an open public space. In INTER-NOISE and NOISE-CON Congress and Conference Proceedings (Vol. 253, No. 7, pp. 1063-1068). Institute of Noise Control Engineering.

[25] Marušić, B. G. (2011). Analysis of patterns of spatial occupancy in urban open space using behaviour maps and GIS. Urban design international, 16(1), 36-50.

[26] Wang, C. (2014). Simulation research on occupant energy-related behaviors in building. Tsinghua University.

[27] Meng, Q., Zhao, T., \& Kang, J. (2018). Influence of music on the behaviors of crowd in urban open public spaces. Frontiers in psychology, 9, 596.

[28] Chen,S. (2009). Research on the Behavioral vigor of Urban Leisure Square. (Doctoral dissertation). Central South University.

[29] Lavia, L., Witchel, H. J., Kang, J., \& Aletta, F. (2016, March). A preliminary soundscape management model for added sound in public spaces to discourage anti-social and support pro-social effects on public behaviour. In Proc $D A G A$ (Vol. 16, pp. 14-17).

[30] Aletta, F., Lepore, F., Kostara-Konstantinou, E., Kang, J., \& Astolfi, A. (2016). An experimental study on the influence of soundscapes on people's behaviour in an open public space. Applied sciences, 6(10), 276.

[31] Caldwell, C., \& Hibbert, S. A. (1999). Play that one again: The effect of music tempo on consumer behaviour in a restaurant. ACR European Advances, 4, 58-64.

[32] Spangenberg, E. R., Crowley, A. E., \& Henderson, P. W. (1996). Improving the store environment: do olfactory cues affect evaluations and behaviors?. Journal of marketing, 60(2), 67-80.

[33] Michon, R., Chebat, J. C., \& Michon, R. (2006). The interaction effect of music and odour on shopper spending. Unpublished doctoral dissertation, School of Retail Management, Ryerson University, Toronto, Canada.

[34] Zhou, X. (2013). Research of noise analysis and reduction methods of cooling fans. (Doctoral dissertation). University of Electronic Science and Technology of China.

[35] Ma, J.F. (2014). The Influence of Different Music Conditions on Drivers' Attention and Hazard Perception. (Doctoral dissertation). Liaoning Normal University.

[36] Tao, L. (2017). Research on the Adaptation and Application of Music to Running. (Doctoral dissertation). Zhejiang University of Technology.

[37] Zahorik, P. (2002). Assessing auditory distance perception using virtual acoustics. The Journal of the Acoustical 
Society of America, 111(4), 1832-1846.

[38] Li, Z., \& Kang, J. (2019). Sensitivity analysis of changes in human physiological indicators observed in soundscapes. Landscape and Urban Planning, 190, 103593.

[39] Zhang, X., Ba, M., Kang, J., \& Meng, Q. (2018). Effect of soundscape dimensions on acoustic comfort in urban open public spaces. Applied acoustics, 133, 73-81.

[40] Meng, Q., \& Kang, J. (2015). The influence of crowd density on the sound environment of commercial pedestrian streets. Science of the total environment, 511, 249-258.

[41] China, M. E. P. (2012). Technical Regulation on Ambient Air Quality Index (on Trial)(HJ633-2012). China Environmental Science Press: Beijing, China.

[42] Sinibaldi, G., \& Marino, L. (2013). Experimental analysis on the noise of propellers for small UAV. Applied Acoustics, 74(1), 79-88.

[43] Husain, G., Thompson, W. F., \& Schellenberg, E. G. (2002). Effects of musical tempo and mode on arousal, mood, and spatial abilities. Music Perception: An Interdisciplinary Journal, 20(2), 151-171.

[44] Ye, P., Wang, H., \& Gao, F. (2012). A preliminary study on the research method of urban public space environment and behavior based on GPS: A case study of Shengli Square in Hefei. Archit. J, 28-33. 